\title{
EXPRESSÃO GÊNICA DIFERENCIAL DURANTE DÉFICIT HÍDRICO EM SOJA
}

\author{
ELAINE CRISTINA CASAGRANDE ${ }^{1}$, JOSÉ RENATO BOUÇAS FARIAS ${ }^{2}$, NORMAN \\ NEUMAIER ${ }^{2}$, TETSUJI OYA ${ }^{3}$, JÚLIO PEDROSO ${ }^{4}$, POLYANA KELLY MARTINS ${ }^{4}$, \\ MICHÈLLE CLAIRE BRETON ${ }^{4}$, ALEXANDRE LIMA NEPOMUCENO ${ }^{2 \phi}$
}

EMBRAPA SOJA, Caixa Postal 231, Londrina - PR

\begin{abstract}
RESUMO - Tolerância à seca em plantas não é uma característica simples, mas sim um complexo de mecanismos que trabalham em conjunto ou isoladamente para evitar ou tolerar períodos de déficit hídrico. Genótipos que diferem em tolerância ao déficit hídrico devem apresentar diferenças qualitativas e quantitativas na expressão gênica quando submetidos a períodos de seca. Três cultivares de soja (BR-4, BR-16 e MG/BR-46 Conquista), com respostas contrastantes ao déficit hídrico, foram estudadas com o uso da técnica "Differential Display" (DD) para identificar e isolar genes que podem apresentar diferenças de expressão durante períodos de seca entre os genótipos estudados. Um total de 84 fragmentos de DNAc diferencialmente expressos foram detectados. Trinta e cinco fragmentos foram clonados em vetores pGEM-T, onde vinte e oito puderam ser seqüenciados. Comparação das seqüências obtidas com seqüências em bancos de genes mostraram identidade de seqüência com genes conhecidos. Um dos clones, por exemplo, mostrou homologia com um ativador de transcrição encontrado em Arabidopsis thaliana, ao passo que outro clone mostrou-se homólogo a uma subunidade de NADH Desidrogenase de Spinacia oleracea. O ativador de transcrição apresentou-se diferencialmente expresso somente em raízes, e o homólogo à subunidade de NADH Desidrogenase foi expresso somente no genótipo considerado tolerante à seca e somente durante a condição de estresse hídrico. Pelos resultados deste trabalho, foi possível identificar alguns fragmentos potencialmente envolvidos em respostas à condição de seca em soja. Com essas informações, o estudo desses genes pode ser aprofundado, visando à confirmação desses resultados e a auxiliar no desenvolvimento de novos genótipos mais adaptados às condições de seca em soja e possivelmente em outras culturas.
\end{abstract}

TERMOS ADICIONAIS PARA INDEXAÇÃO: RNA mensageiro, "Differential Display”, seca, expressão gênica, NADH Desidrogenase, Ativador de Transcrição.

Recebido: 19.06.2001 - Aceito em 09/08/2001

1. MSc, Genética e Melhoramento, Universidade Estadual de Londrina-UEL, Londrina - PR.

2. PhD, Embrapa Soja, Caixa Postal 231, Londrina, PR, anepo@ cnpso.embrapa.br. ${ }^{\phi}$ Autor p/ correspondência.

3. PhD, Centro Internacional de Pesquisas em Ciências Agrícolas do Japão - JIRCAS, Tsukuba, Japão.

4. Estudante do curso de Mestrado em Genética e Melhoramento, UEL, Londrina - PR. 


\title{
DIFFERENTIAL GENE EXPRESSION IN SOYBEAN DURING WATER DEFICIT
}

\begin{abstract}
Tolerance to drought in plants is not a simple trait, but rather a complex of mechanisms working in combination to avoid or to tolerate water deficit. Genotypes that differ in tolerance to water deficit would have qualitative and quantitative differences in gene expression when submitted to periods of drought. Three soybean cultivars (BR-4, BR-16 and MG/BR-46 Conquista) with contrasting responses to water deficit stress were studied by using the "Differential Display" (DD) technique to identify and isolate genes which may differ among these cultivars. A total of 84 cDNA fragments differentially displayed were detected. These fragments were extracted from the DD gels and reamplified. Third-five reamplified fragments were cloned in pGEM-T vectors. From these, 28 clones were able to be sequenced. Search of gene bank databases showed, for example, that two cDNA clones, A1B2-1 and A1B1-8 have high homology with a Transcription Activator found in Arabidopsis thaliana and a NADH Dehydrogenase ND4L subunit found in Spinacia oleracea, respectively. The clone A1B2-1 was found differentially expressed only in roots. Clone A1B1-8, on the other hand, was expressed only in a drought tolerant cultivar and only during a water deficit situation. The results of this work allowed a screening of part of the expressed genes during a drought situation in soybean. Now the study of these expressed genes can be deepened to confirm these results and to help the development of new drought tolerant soybean genotypes.
\end{abstract}

ADDITIONAL INDEX TERMS: mRNA, Differential Display, drought, gene expression, NADH Dehydrogenase, Transcription Activator.

\section{INTRODUÇÃO}

O clima é o principal fator responsável pelas oscilações anuais de produção de grãos no Brasil (Camargo, 1984). Em relatório sobre segurança agrícola, elaborado pelo Ministério do Planejamento (Göpfert et al., 1993), consta a ocorrência de secas como principal evento sinistrante $(71 \%$ dos casos), seguida por chuva excessiva (22\% dos casos), granizo, geada, pragas e doenças. Nas secas ocorridas nas safras 1977/78 e 1978/79, nos três Estados da Região Sul do Brasil, deixou-se de colher aproximadamente 7,2 milhões de toneladas de grãos de soja (Farias et al., 1993), o que equivale hoje a aproximadamente U\$ 1,5 bilhão. Especificamente no Estado do Paraná, nas safras de $1977 / 78$ e 78/79, e mais recentemente nas safras 85/86 e 99/00, ocorreram perdas na produção em torno de $31 \%, 30 \%, 22 \%$ e $9 \%$, respectivamente, em consequiência de déficits hídricos (Miyasaka e Medina, 1981; Bergamaschi et el., 1986). No Rio Grande do Sul, a EMATER estimou uma redução de quase $30 \%$ na safra gaúcha de soja (98/99) em virtude de problemas de seca. Nesse mesmo Estado, a severidade das perdas pôde ser constatada principalmente na safra 1990/91, quando chegaram próximas a $70 \%$, caindo de um rendimento médio de grãos de 2000 $\mathrm{Kg} / \mathrm{ha}$ (em 1989/90) para $750 \mathrm{Kg} / \mathrm{ha}$ (Embrapa, 1998).

A água constitui aproximadamente $90 \%$ do peso da planta, atuando em praticamente todos os processos fisiológicos e bioquímicos. Desempenha a função de solvente, por meio do qual gases, minerais e outros solutos entram nas células e movem-se na planta. Tem, ainda, papel importante na regulação térmica da planta, agindo tanto no resfriamento como na manutenção e distribuição do calor (Norman e Nepomuceno, 1994).

O efeito da deficiência hídrica na produção depende da época de ocorrência e de sua severidade. Em soja, nas fases de germinação e emergência, diminui o estande de plantas. No florescimento, causa o aborto das flores e impede a antese, enquanto no enchimento dos grãos, afeta o 
peso dos grãos e, conseqüentemente, a produção (Berlato, 1981; Fageria, 1989). A falta de água pode afetar ainda a eficiência do processo fotossintético, tanto de forma direta, com a desidratação do citoplasma, como indiretamente, devido ao fechamento estomático (Miyasaka e Medina, 1981). Mudanças morfológicas, fisiológicas e de desenvolvimento de plantas apresentam bases moleculares e genéticas. Portanto, a caracterização de genótipos tolerantes ou sensíveis à seca é um pré-requisito para seleção e manipulação genética (Turner, 1997). A identificação e a compreensão dos mecanismos de tolerância à seca em plantas são cruciais no desenvolvimento de novas cultivares de soja mais tolerantes. A expressão diferencial de genes ainda não identificados em genótipos tolerantes pode ser usada para o estudo desses mecanismos de tolerância (Shinozaki e Yamaguchi-Shinozaki, 1996, 1997). Uma resposta fisiológica específica ao déficit hídrico representa na verdade combinações de eventos moleculares que são ativados ou desativados pela percepção do estresse (Bray, 1993). Entender como eventos interagem entre si será um passo importante no desenvolvimento de maior tolerância à seca.

Existe uma série de metodologias usadas para a identificação e isolamento de genes expressos diferencialmente. Entre as metodologias que mais se destacam hoje estão Library Subtraction (biblioteca de subtração), Differential Display - DD (apresentação diferenciada) e DNA MicroArrays (micro arranjos de DNA) (Freeman et al., 2000). Esta última técnica, apesar de proporcionar volume muito grande de informações, quando comparada com as outras duas técnicas, é bastante cara, o que limita seu uso em muitos laboratórios. A técnica $D D$, entretanto, apesar de gerar menor volume de informações que DNA Microarrays, é relativamente de baixo custo e de fácil implementação em qualquer laboratório de biologia molecular. A técnica foi apresentada pela primeira vez em 1992 (Liang e Pardee, 1992), e tem assumido uma grande importância no descobrimento de novos genes envolvidos em vários processos metabólicos tanto em plantas quanto em animais (Wilkinson et al., 1995; Wilkins et al., 1998).

Considerando-se tolerância à seca como uma característica poligênica e difícil de ser trabalhada no melhoramento genético clássico, poucos programas de melhoramento se preocupam com essa característica (Beever, 2000). Conseqüentemente, poucos cultivares têm sido desenvolvidos com características de tolerância à seca. Dessa maneira, a biologia molecular assume papel-chave na identificação pontual de genes envolvidos nas respostas ao déficit hídrico, o que permitirá futuramente a identificação e a compreensão de rotas metabólicas envolvidas nas respostas fisiológicas à seca. Isso permitirá o uso desses genes como sondas moleculares em programas de melhoramento que busquem a identificação de genótipos e expressem mecanismos metabólicos que aumentem sua tolerância às condições de deficiência hídrica. Existe também a possibilidade pela engenharia genética, transformando-se plantas, de se transferir genes de interesse para outros genótipos, assim como, entre espécies incompatíveis (Beever, 2000). Com este trabalho objetivou-se identificar, clonar e seqüenciar genes diferencialmente expressos em três genótipos de soja submetidos a períodos de restrição no fornecimento de água.

\section{MATERIAL E MÉTODOS}

A escolha dos genótipos de soja baseouse nos resultados de experimentos anteriores, nos quais se constatou que os cultivares BR-4 e BR-16 apresentavam distintas respostas quando submetidos a períodos de déficit hídrico. BR-4 apresenta-se com maior capacidade de tolerar períodos de falta de água, enquanto BR-16 mostrase bastante sensível à deficiência hídrica (Nepomuceno et al., 1994; Neumaier e Nepomuceno, 1994; Farias et al., 1995; Neumaier et al., 1995; Neumaier et al. 1997, Farias et al., 1998). Por se tratar de um novo material, o cultivar MG/BR-46 Conquista não participou dos trabalhos prévios de caracterização. Entretanto, várias observações empíricas feitas por melhoristas de 
soja e produtores (comunicação pessoal) sugerem esse cultivar com alta capacidade de tolerância a períodos de déficit hídrico, o que provocou sua inclusão na caracterização molecular de respostas ao déficit hídrico deste trabalho.

A semeadura do experimento foi realizada em vasos de PVC, em casa-de-vegetação. Foram utilizados $6,5 \mathrm{~kg}$ de substrato/vaso com a composição de $50 \%$ vermiculita e $50 \%$ de areia grossa lavada. Para indução do déficit hídrico, as plantas foram submetidas a dois níveis de umidade gravimétrica no solo, $5 \%$ e $15 \%$, correspondendo aos tratamentos estressado e não estressado, respectivamente. Esses valores foram mantidos por meio de pesagem diária dos vasos, excluindo-se o peso aproximado das plantas, que foi estimado utilizando-se vasos-controle com os mesmos tratamentos. A diferenciação entre os tratamentos ocorreu somente no início do período reprodutivo, ocorrido aos 50 dias após a emergência. Antes dessa fase, os tratamentos foram mantidos a $15 \%$ de umidade gravimétrica do solo. No interior da casa-de-vegetação, a temperatura foi mantida entre 23 e $28^{\circ} \mathrm{C}$, sem controle de umidade relativa do ambiente e do fotoperíodo. $\mathrm{O}$ experimento foi instalado segundo um delineamento em blocos completos casualizados com três repetições. Após a emergência, foi feito o desbaste, deixando-se duas plantas por vaso.

Coletou-se 1 grama de tecido (foliar e radicular) de cada tratamento, para extração de RNA total, 13 dias após a diferenciação dos tratamentos, o que ocorreu no início da floração. Rapidamente, os tecidos coletados foram lavados em água corrente a fim de eliminar pequenos insetos ou outros organismos que pudessem estar na superfície de folhas e raízes. As amostras foram então armazenadas em papel-alumínio e colocadas imediatamente em nitrogênio líquido, a fim de evitar ação das RNases. Imediatamente após a coleta, o RNA total oriundo de cada tratamento foi extraído com o uso do reagente Trizol (Life Technologies - Gibco BRL). O RNA total foi utilizado em reações de transcrição em reverso (RT), em que foram usados os seguintes primers âncora: $\mathrm{A} 1{ }^{5^{\prime}} \mathrm{T}_{(9)} \mathrm{GC}^{3}, \mathrm{~A} 2:^{5^{\prime}} \mathrm{T}_{(9)} \mathrm{CC}^{3}{ }^{\prime}, \mathrm{A} 3:^{5^{\prime}} \mathrm{T}_{(9)} \mathrm{GG}^{3^{\prime}} \mathrm{e}$
A4: ${ }^{5} \mathrm{~T}_{(9)} \mathrm{CG}^{3}$. O volume final das reações de RT para cada tratamento foi de $50 \mu \mathrm{L}$, e cada reação foi composta de: $3 \mu \mathrm{L}$ de RNA $(2 \mu \mathrm{g} / \mu \mathrm{L}) ; 10 \mu \mathrm{L}$ de

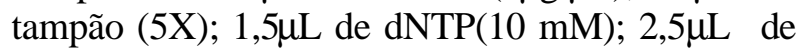
primers âncora $(50 \mu \mathrm{M}),(\mathrm{A} 1, \mathrm{~A} 2, \mathrm{~A} 3$ ou A4) e $31,5 \mu \mathrm{L}$ de água DEPC. A reação foi levada ao termociclador a $65^{\circ} \mathrm{C}$ por $5 \mathrm{~min}$. Quando a temperatura caiu para $37^{\circ} \mathrm{C}$, acrescentou-se à reação $1,5 \mu \mathrm{L}$ da enzima M-MLV RT (Life Technologies - GIBCO BRL). Incubou-se a $37^{\circ} \mathrm{C}$ por uma hora e depois a temperatura foi elevada para $99{ }^{\circ} \mathrm{C}$, durante $5 \mathrm{~min}$. Depois da reação RT, foram feitas reações de PCR radioativo usando-se as combinações dos primers âncora (A1,A2,A3 e A4) com os primers randômicos (10-mer) B1 $\left({ }^{5^{\prime}}\right.$ GAGCTTGAAC $\left.^{3^{\prime}}\right)$, B2 $\left({ }^{5^{\prime}}\right.$ GTGCGTCCTC $\left.^{3^{\prime}}\right)$, e $\mathrm{B} 7\left({ }^{5} \mathrm{CCGTCACTGG}^{3}\right)$. O volume final da reação de PCR foi de $25 \mu \mathrm{L}$, com a seguinte composição: $4 \mu \mathrm{L}$ de DNAc; $6,25 \mu \mathrm{L}$ de dNTP $(100 \mu \mathrm{M}) ; 2,5 \mu \mathrm{L}$ de tampão $(10 \mathrm{X}) ; 1,25 \mu \mathrm{L}$ de $\mathrm{MgCl}_{2}(50 \mathrm{mM}) ; 1 \mu \mathrm{L}$ de primers âncora $(50 \mu \mathrm{M})$; $0,5 \mu \mathrm{L}$ de Taq DNA polymerase $(5 \mathrm{U} / \mu \mathrm{L})(\mathrm{Life}$ Technologies - GIBCO BRL); 8,7 $\mu \mathrm{L}$ de água DEPC; $\quad 0,3 \mu \mathrm{L}$ de $\left[\alpha-{ }^{33} \mathrm{P}\right] \mathrm{dATP} \quad(10 \mathrm{mCi} / \mathrm{mL}$, 2500Ci/m mol, Amersham Pharmacia Ltda) e $0,5 \mu \mathrm{L}$ de primer randômico $(50 \mu \mathrm{M})(\mathrm{B} 1, \mathrm{~B} 2$, ou B7). As temperaturas de amplificação utilizadas foram as seguintes: $2 \mathrm{~min}$ a $94^{\circ} \mathrm{C}$, seguido de 40 ciclos de $94^{\circ} \mathrm{C}$ por $30 \mathrm{~s}, 42^{\circ} \mathrm{C}$ por $1 \mathrm{~min}$ e $72^{\circ} \mathrm{C}$ por 30 s, e uma extensão final a $72^{\circ} \mathrm{C}$ por $5 \mathrm{~min}$.

Os produtos de PCR de cada subgrupo (cada tratamento aplicado) foram separados por tamanho molecular em géis de seqüenciamento. Após auto-radiografia, as bandas foram analisadas e comparadas entre os diferentes tratamentos. Bandas que se apresentaram de forma diferente no gel (e.g., bandas presentes em uma situação de estresse e somente em genótipos tolerantes ao déficit hídrico) foram extraídas; o DNAc dessa banda foi separado do gel (purificado) e reamplificado (Song et al., 1995; Nepomuceno et al., 1998). Após reamplificação, o produto de PCR foi inserido em vetores de clonagem pGEM-T (Promega corp.). Cada produto de PCR reamplificado foi quantificado e misturado com o vetor numa razão molar de aproximadamente 6:1 
(fragmento:vetor). Plasmídeos pGEM-T com os fragmentos inseridos foram usados para transformar Escherichia coli (cepa JM109) segundo Sambrook et al. (1989). Características do plasmídeo pGEM-T permitem que colônias transformantes sejam separadas de colônias não transformantes mediante seleção pela cor da colônia em meio de cultura. A extração e purificação dos plasmídeos recombinantes foi feita com o uso do kit Wizard $\AA P l u s$ midipreps (Promega Corp.). Seqüências de DNA reconhecidas por enzimas de restrição flanqueando o ponto de inserção do fragmento no vetor foram usadas para restringir o fragmento inserido $\mathrm{e}$ confirmar a clonagem. O seqüenciamento dos clones foi feito com o kit ABI Prism BigDye terminator cycle sequencing (Applied Biosystems) no equipamento ABI Prism 377 (Applied Biosystems).

\section{RESULTADOS E DISCUSSÃO}

Foram identificados 84 fragmentos de DNAc diferencialmente expressos, e foi possível clonar 35 fragmentos no vetor de clonagem pGEM-T Easy Vector e seqüenciar 28 desses fragmentos. Com a obtenção das sequiências, foi estudada a homologia com seqüências de genes já conhecidos. Esse procedimento foi feito através do uso do programa BLAST2 (Altschul et al., 1990) junto ao Laboratório Europeu de Biologia Molecular - EMBL (http://www.bork.emblheidelberg.de/Blast2/). Depois de realizadas as buscas em bancos de genes, 15 seqüências apresentaram alta homologia com genes conhecidos, 9 apresentaram baixa homologia e 4 seqüências não apresentaram homologia.

Toda expressão fenotípica em plantas submetidas ao déficit hídrico está relacionada com a expressão gênica e sua interação com o ambiente. Quando água é perdida pela célula, processos regulatórios são iniciados e o metabolismo celular é ajustado às novas condições celulares (Bray,
1997). Simultaneamente, inibição no crescimento e alterações no desenvolvimento começam a ocorrer, resultando em mudanças adicionais na expressão gênica (Bray, 1993). Muitos genes induzidos pelo déficit hídrico provavelmente promovem aumento da tolerância celular à desidratação, aumento das funções de proteção do citoplasma, organelas e membranas celulares, alterações do potencial celular osmótico, aumento na absorção de água (e.g. aquaporins), aumento no controle e no acúmulo de íons e maior regulação da expressão de outros genes (Bray, 1993, 1997; Bohnert, et al. 1995; Shinozaki e Yamaguchi-Shinozaki, 1997).

Algumas das bandas diferencialmente expressas que mostraram homologia puderam ser associadas com rotas metabólicas que podem estar envolvidas em respostas ao déficit hídrico. Confirmações definitivas da homologia com genes conhecidos e de suas funções virão somente após o isolamento e seqüenciamento completo dos RNAm, assim como a correlação com as características agronômicas e fisiológicas de tolerância à seca. Entretanto, considerando-se que centenas de genes estão envolvidos em resposta ao déficit hídrico, esse tipo de análise mais ampla torna-se importante, pois genes-chave podem ser identificados e, posteriormente, podem ser estudados e analisados em grande profundidade.

A banda A1B2-1 (Figura 1), que gerou o clone A1B2-1 apresentou-se diferencialmente expressa somente em raízes das cultivares BR-16 e MG/BR-46 Conquista, em ambas as situações de água no solo (Tabela 1). Essa banda gerou um fragmento de 306 pares de bases, em que um dos quadros de leitura mostrou alta homologia com um ativador de transcrição de Arabidopsis thaliana ( $n^{\circ}$ acesso: Trembl/AC005397). A seqüência de aminoácidos do Ativador de Transcrição de Arabidopsis thaliana comparada com a do clone A1B2-1 apresenta 47 aminoácidos homólogos, mostrando homologia de $89 \%$ entre eles para aquela região (Figura 2). 


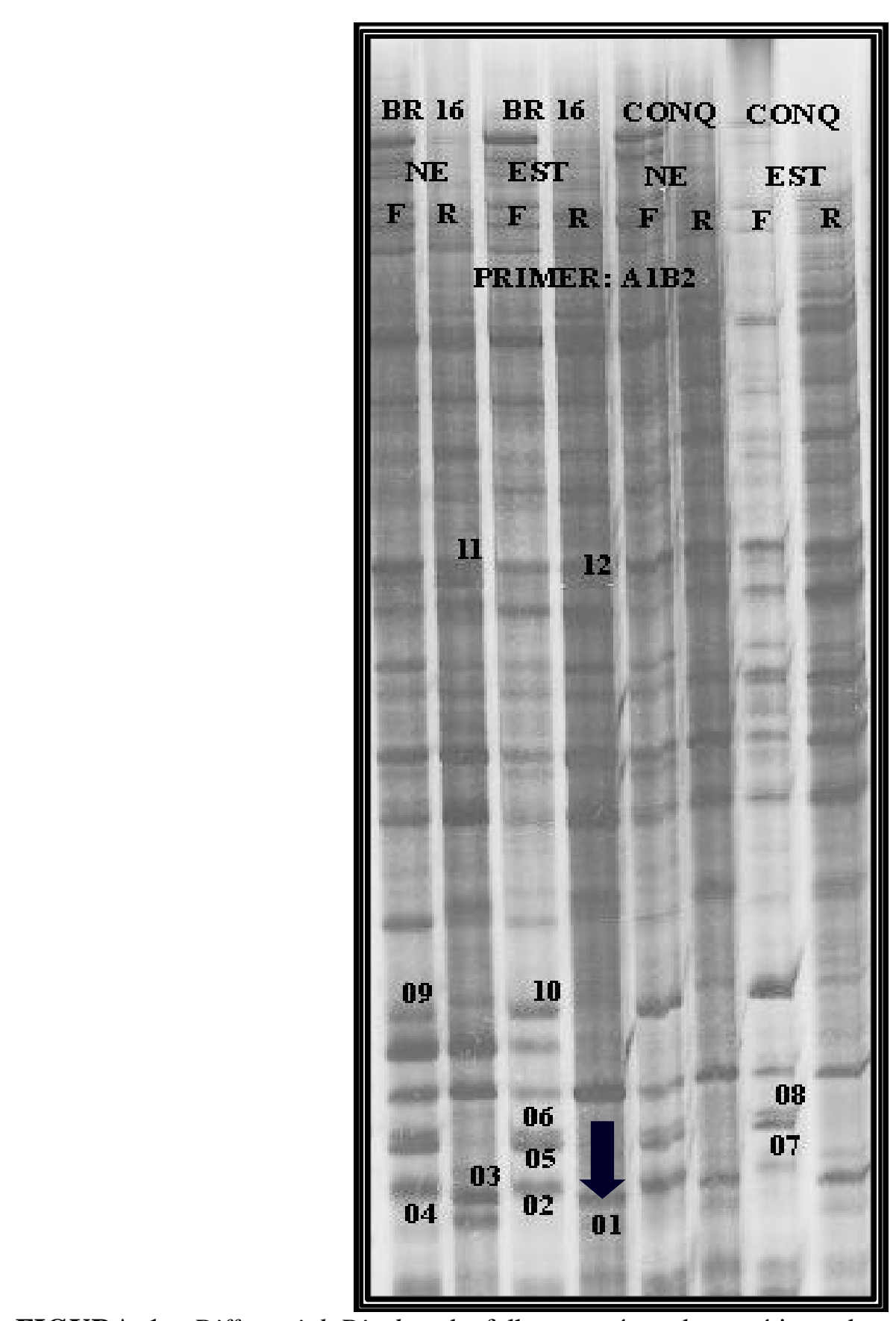

FIGURA 1 - Differential Display de folhas e raízes de genótipos de soja - BR-16 e MG/BR-46 Conquista (CONQ), após períodos de déficit hídrico. A banda A1B2-1 apresentou-se diferencialmente expressa em raízes dos cultivares MG/BR-46 Conquista e BR-16, sob a condição de déficit hídrico e condição ótima de água no solo. NE - Não Estressado; EST - Estressado; F -Folha; R - Raiz. 


\section{Quadro de leitura $\left(3^{\prime},+3\right)$ do clone A1B2-1}

gtgcgtcctcggacagtcaaagagtgagacagatrgtatcaccatcagtctcctctcagaaa

$\begin{array}{llllllllllllllllllll}A & S & S & D & S & Q & R & V & R & Q & X & V & S & X & S & V & S & S & Q & K\end{array}$ tttggttccctctctgcattagatgctcggccaagctccatttctaaaaggatggtatgt

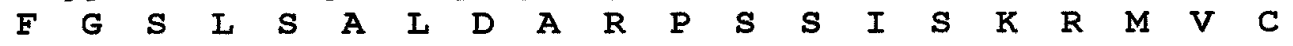
tgctatacttgatttttttcagtagttgtttgttctatctcattcttaataatatctt

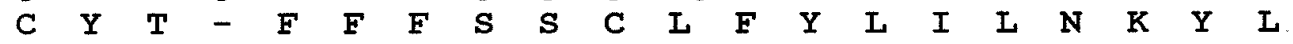
tatgatgatttttggcagacagatgagttagaggaaggggaaattgcggtatctggtgat $\begin{array}{llllllllllllllllllll}Y & D & D & F & W & \mathcal{Q} & T & D & E & L & E & E & G & E & I & A & V & S & G & D\end{array}$ tctcacatggaccatcaattgtctggaagttggattcatgatcgtgatgaaggtgaggac $\begin{array}{llllllllllllllllllll}\mathbf{S} & \mathrm{H} & \mathbf{M} & \mathrm{D} & \mathrm{H} & \boldsymbol{Q} & \mathrm{L} & \mathbf{S} & \mathbf{G} & \mathbf{S} & \text { W } & \text { I } & \text { H } & \mathbf{D} & \mathbf{R} & \mathrm{D} & \mathbf{E} & \mathbf{G} & \mathbf{E} & \mathrm{D}\end{array}$ gcac

A

Homologia com: Proteína Hipotética de 141.4 KDa pertencente a subfamília global de Ativadores de transcrição.

Registro de Acesso (Gene Bank): sptrembl|082366|082366

Probabilidade BLASTX2 P(2): $1.0 \mathrm{e}-12$

Identidades $=40 / 53(758)$, Positivos $=47 / 53$ (88\%)

$\begin{array}{lrl}\text { A1B2-1: } & 60 \text { KFGSLSALDARPSSISKRMV } 119 \\ & \text { KFGSLSALD RP S+SKR++ } \\ \text { Homólogo: } & 773 \text { KFGSLSALDTRPGSVSKRLI } 792 \\ \text { A1B2-1: } & 204 \text { DELEEGEIAVSGDSHMHQLSGSWIHDRDEGED } 302 \\ \text { Homólogo: } & \begin{array}{l}\text { D+LEEGEIA SGDSH+D Q SGSW HDRDEG++ } \\ \text { DDLEEGEIAASGDSHDLQRSGSWAHRDEGE } 825\end{array}\end{array}$

FIGURA 2 - Resultado obtido junto ao programa BLASTX2, comparando-se as sequiências de aminoácidos geradas a artir da banda A1B2-1 com as sequiências de aminoácidos do Ativador de Transcrição de Arabdopsis thaliana. 
Fatores (ativadores) de transcrição, normalmente são proteínas necessárias para iniciar a transcrição. A categoria dos fatores de transcrição gerais, chamados TFII estão presentes em todas as células do organismo e sem eles a transcrição não ocorre corretamente (Lewin, 2000). Existem os fatores de transcrição que normalmente são proteínas induzidas a serem expressas durante situações específicas de desenvolvimento ou interação com o ambiente, ou que são expressas somente em tecidos específicos no organismo (Dey e Harborne, 1997). Estes normalmente são chamados de Ativadores de Transcrição ou transfactors, entretanto, executam papel semelhante aos ativadores de transcrição, pois atuam diretamente sobre a RNA polimerase, sobre o promotor do gene, ou sobre algum outro elemento que interfira com a transcrição (Lewin, 2000).

Como a banda A1B2-1 mostrou-se homóloga a um ativador de transcrição e apresentou-se diferencialmente expressa somente em raízes, esse fragmento torna-se importante na identificação do elemento promotor da expressão deste gene, pois o isolamento dessa sequiência promotora poderá ser usada em construções gênicas que visem a expressão de proteínas específicas somente em raízes de soja. Apesar de existir ainda o trabalho de isolamento deste promotor, esta possibilidade somente foi visualizada a partir da identificação deste gene diferencialmente expresso somente em raízes de soja.

A banda A1B1-8 (Figura 3) representa um fragmento de 497 pares de bases que se apresentou diferencialmente expresso somente em folhas do cultivar MG/BR-46 Conquista e somente na condição de estresse hídrico. A tradução de um dos quadros de leitura do fragmento clonado A1B1-8, mostrou alta homologia com a subunidade ND4L da enzima NADH desidrogenase encontrada em Spinacea oleracea ( $n^{\circ}$ acesso: Trembl/AJ400848), onde há uma região apresentando 44 aminoácidos homólogos (64\% homologia)(Figura 4). NADH desidrogenases são enzimas componentes da membrana mitocondrial. Estão diretamente envolvidas no transporte de elétrons na cadeia respiratória (Fosforilação
Oxidativa), e conseqüentemente, têm papel chave no fornecimento de energia na célula (Dey \& Harborne, 1997). A identificação desta enzima diferencialmente expressa em um cultivar tolerante à seca abre a possibilidade desta ser uma isoenzima homóloga mais eficiente em termos de atividade enzimática. Formas múltiplas de enzimas com a mesma função são chamadas de isoenzimas (Lehninger, et al. 1993). Essas enzimas ocorrem em mais de uma forma molecular em uma espécie, em um mesmo tecido, ou até em uma mesma célula. Em tais casos as diferentes formas da enzima catalisam a mesma reação, entretanto, mesmo pequenas diferenças na composição e seqüência de aminoácidos podem afetar as propriedades catalíticas da enzima e, conseqüentemente, alterar a atividade da mesma. A identificação de uma isoenzima de NADH desidrogenase diferencialmente expressa durante condições de déficit hídrico num cultivar tolerante pode estar relacionada à produção de energia neste cultivar e, conseqüentemente, nas diferenças encontradas com relação a maior ou menor tolerância ao déficit hídrico.

A banda A1B2-12 apresentou-se diferencialmente expressa em raízes dos cultivares BR-16 e MG/BR-46 Conquista, tanto na situação ótima de água no solo como na situação de estresse hídrico (Tabela 1). Essa banda gerou um fragmento de 506 pares de bases cuja seqüência de aminoácidos apresenta alta homologia com a enzima UDP-AcetilGlucosamina Pirofosforilase do Cromossomo II de Arabidopsis thaliana ( $n^{-}$ acesso: Trembl/AC004238). Esta enzima esta diretamente envolvida na degradação de sacarose em glicose e frutose. A sacarose vinda através do floema para a raiz deve ser rapidamente degradada a fim de permitir o uso da glicose e frutose como fonte de carbono para os processos de respiração e produção de energia (Spychalla et al., 1994). Conseqüentemente, os níveis de expressão dessa enzima são cruciais no metabolismo radicular. Entretanto, não foi observada diferença de expressão quando se comparou raiz de BR-16 e Conquista, sensível e tolerante à seca, respectivamente, o que diminui, em teoria, 


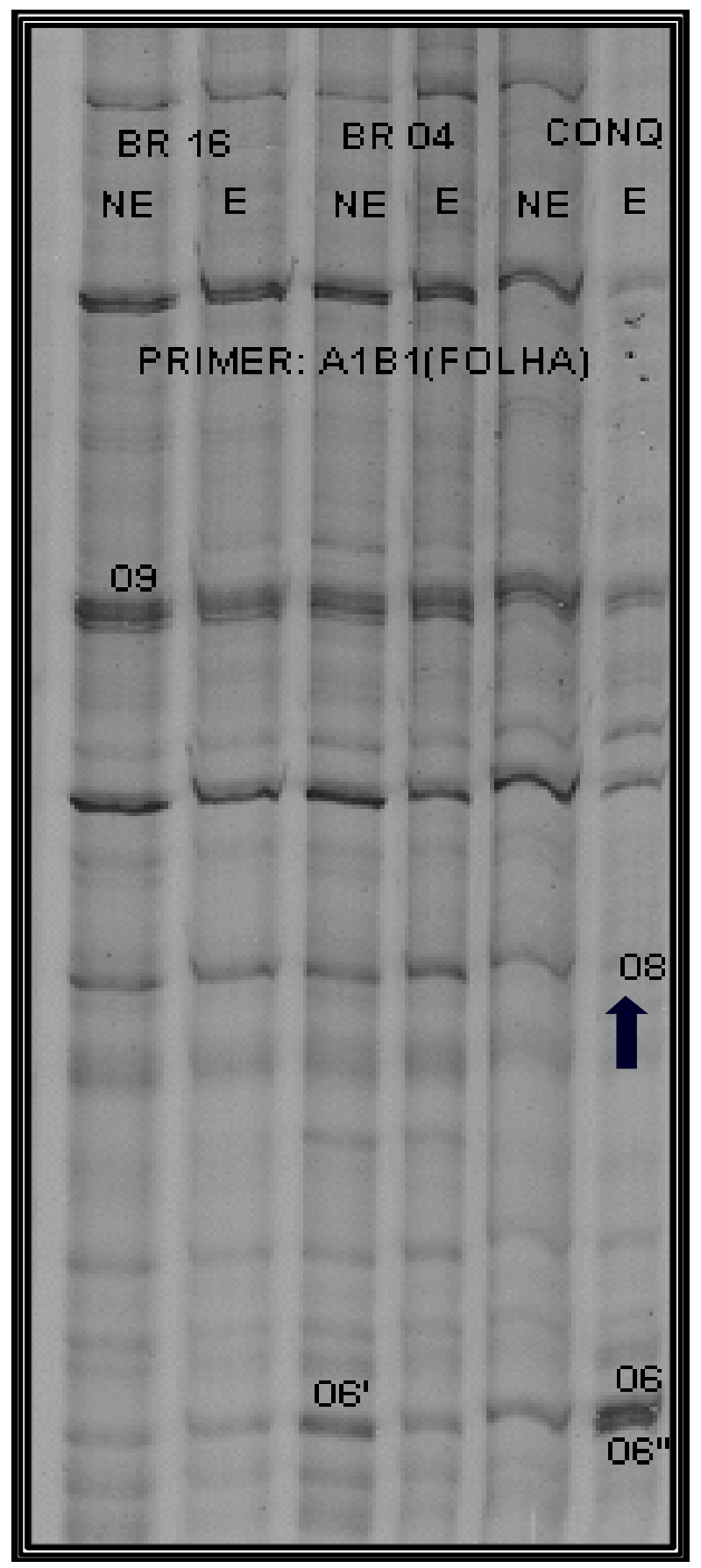

FIGURA 3 - Differential Display de três genótipos de soja: BR-16, BR-4 e MG/BR-46 Conquista, após períodos de déficit hídrico e condição ótima de água no solo. A banda A1B1-8 apresentou-se diferencialmente expressa em folhas da Cultivar MG/BR-46 Conquista sob a condição de déficit hídrico. NE - Não Estressado; E - Estressado. 


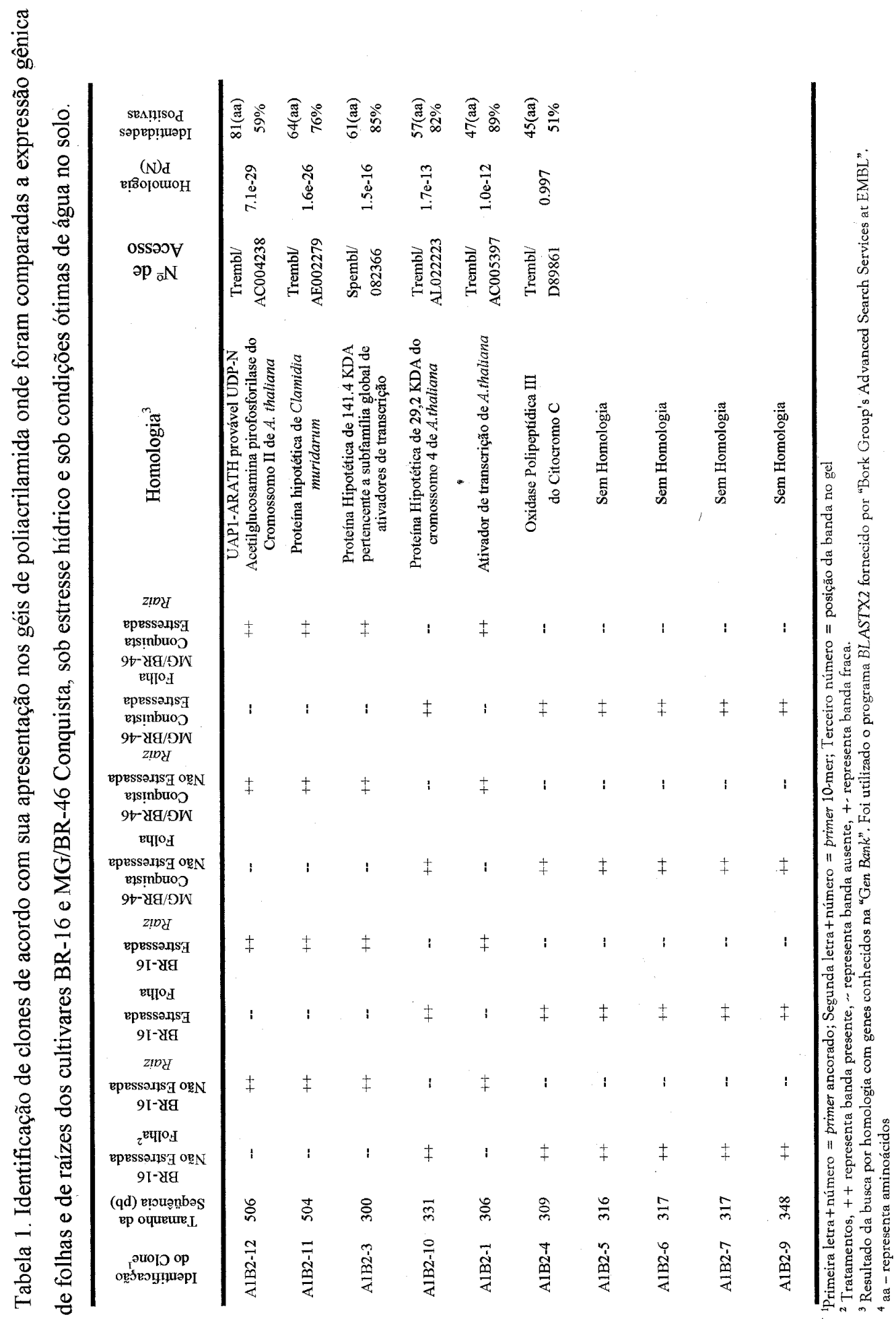

R. Bras. Fisiol. Veg., 13(2): 168-184, 2001 
as chances de essa enzima estar diretamente ligada às diferenças em tolerância à seca observada entre as duas cultivares mencionadas. Contudo, a identificação e isolamento da seqüência promotora que flanqueia esse gene podem vir a ser usados em futuras construções gênicas

A mesma situação das bandas A1B2-1 e A1B2-12 ocorreu com a banda A1B2-11, que se apresentou diferencialmente expressa também em raízes das cultivares BR-16 e MG/BR-46 Conquista, tanto na situação ótima de água no solo como na situação de estresse hídrico (Tabela 1). Essa banda gerou um fragmento de 504 pares de bases, cuja tradução de um de seus quadros de leitura encontrou alta homologia a uma proteína hipotética (provável proteína, mas ainda sem função definida) de Clamidia muridarum ( $n^{o}$ acesso: Trembl/AE002279). Já a banda A1B2-10 apresentou-se diferencialmente expressa somente em folhas dos cultivares BR-16 e MG/BR-46 Conquista, tanto na situação ótima de água no solo como na situação de estresse hídrico (Tabela 1). Essa banda gerou um fragmento de 331 pares de bases cuja tradução de um de seus quadros de leitura apresentou alta homologia com uma proteína hipotética de 29,2 KDA do cromossomo 4 de Arabdopsis thaliana (no acesso: Trembl/AL022223).

A banda A3B2-1 foi obtida a partir de RNAm de folhas e somente não foi expressa no cultivar BR-16 durante a situação ótima de água no solo (Tabela 2). Esse fragmento de 508 pares de bases apresentou a tradução de um de seus quadros de leitura com homologia com um transportador de aminoácidos (Aap3) presente em membranas de Nepentes alata ( $n^{\circ}$ acesso: Trembl/AF08544), uma planta carnívora (Figura 5). A absorção de nutrientes muito provavelmente depende da expressão ou regulação de proteínas transportadoras específicas. Genes que codificam transportadores de aminoácidos tem sido descritos em várias plantas, principalmente em Arabidopsis (Fisher et al., 1998). Transportadores de aminoácidos pertencem a duas diferentes subfamílias, a família de facilitadores de transporte (e.g. amino acid-polyamine-choline (APC)) e a família de transportadores de aminoácidos (ATF). A família ATF pode ainda ser dividida em três subfamílias. A subfamília das permeases de aminoácidos (AAP), a subfamília dos transportadores de lisina-histidina (LHT) e a subfamília dos transportadores de prolina e auxinas (Frommer et al., 1995). A sequiência obtida a partir da banda A3B2-1 mostrou alta homologia com um transportador de aminoácidos da classe das permeases. Essa classe de transportadores tem sido sugerida como uma proteína- chave nos processos de fluxo de aminoácidos para o floema, no suprimento de embriões com aminoácidos e mesmo na absorção de aminoácidos pelas raízes. Seu papel funcional exato ainda necessita de maior detalhamento, entretanto, sabe-se que esses transportadores possuem um amplo espectro de moléculas sobre as quais atua (e.g. aminoácidos, amidas e ureídios). Em plantas carnívoras da espécie Nepentes alata, por exemplo, esse transportador parece ter a função de transferir os aminoácidos obtidos da digestão dos insetos capturados para dentro do sistema vascular da planta (Schulze et al., 1999).

No presente trabalho, esse gene parece ter sido diferencialmente expresso nas folhas de todos os genótipos, com exceção da cultivar BR-16 sob condições ótimas de água no solo. Não está claro o porquê de nesse cultivar este transportador de aminoácidos ser expresso somente durante a situação de déficit hídrico. Várias hipóteses podem ser levantas, entre elas a de que durante situações de seca este genótipo desenvolveu, dentro de sua linha evolutiva, mecanismos de aumento na absorção de compostos nitrogenados.

Em soja, a simbiose entre as raízes da planta e a bactéria Bradrhizobium sp. promove a produção de aminoácidos, ureídios e amidas, que são descarregadas no xilema e levadas até as folhas para utilização (Salisbury \& Ross, 1992). Diferenças entre cultivares com relação a maior ou menor capacidade de absorver e utilizar esses compostos na folha podem estar relacionadas com a presença ou não, ou com os níveis de expressão de proteínas transportadoras de aminoácidos. A redução na metabolização de compostos 


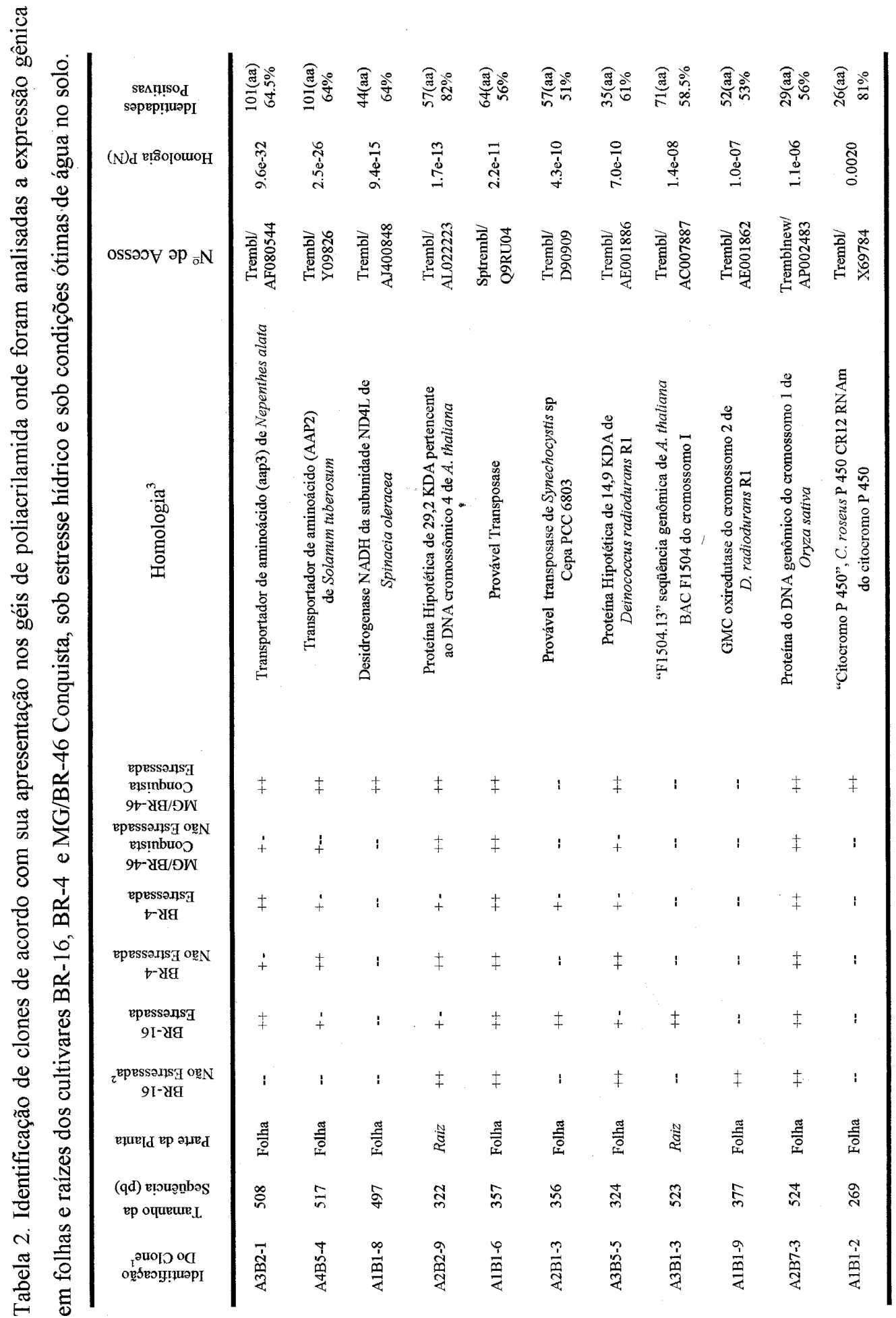




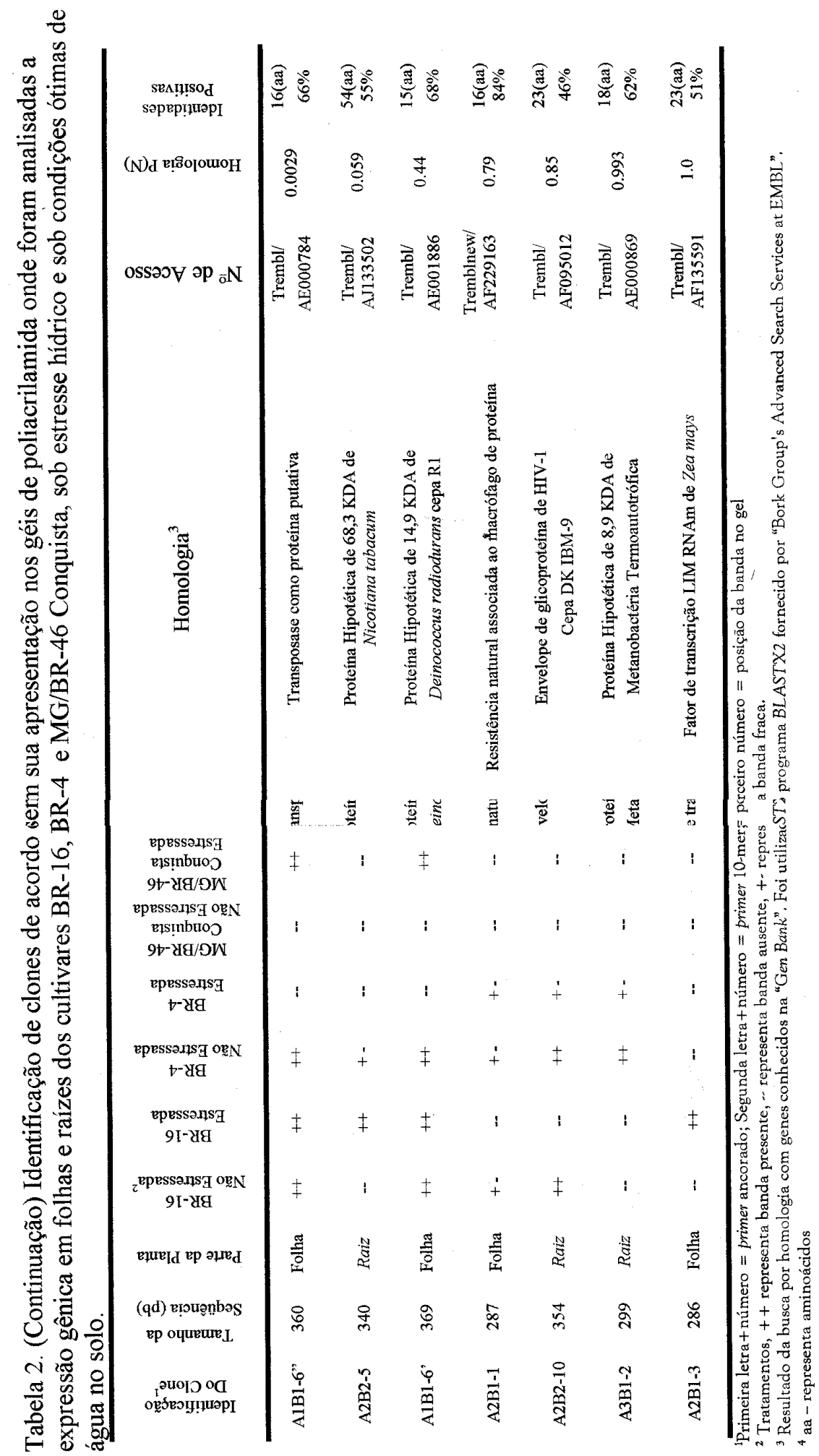




\section{Quadro de Leitura $\left(3^{\prime},-1\right)$ do clone A1B1-8}

gagcttgaacttatactgaatgcagttaatataaatctcgtaacctttctgatttttt

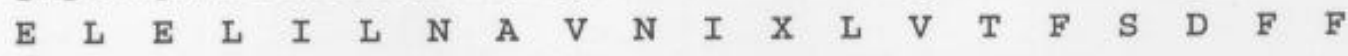
gatagrcgccaattaaabggbaatattttrcaattttgttatagctattgcagctgct

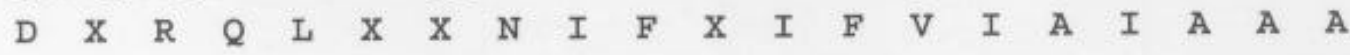
gaagcagctatcggactggctattgtttcctcaatttatcgtaatagaaaatcaacccgt

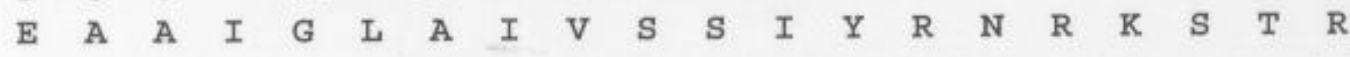
atcaatcaatcaaatttattgaataaataatattaccccataaaaataaaaaagtata $\begin{array}{llllllllllllllllllll}I & \mathrm{~N} & Q & \mathrm{~S} & \mathrm{~N} & \mathrm{~L} & \mathrm{~L} & \mathrm{~N} & \mathrm{~K} & - & \mathrm{Y} & \mathrm{Y} & \mathrm{P} & \mathrm{I} & \mathrm{K} & \mathrm{N} & \mathrm{K} & \mathrm{K} & \mathrm{S} & \mathrm{I}\end{array}$ atttatatttgtgtgtactattaatgaattcaaattagcataagcatatatgatatata

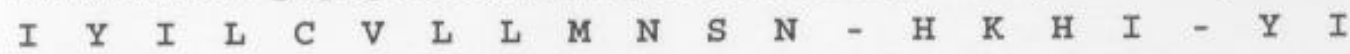
aatagaatcatgtttgcgaaaacaaagataagaaatcaaagtatcttggttctattctc

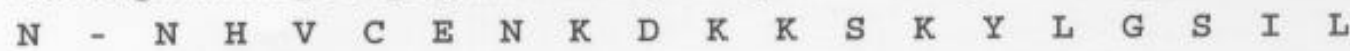
ttattattaattaatctataagtatatttgattatcaaattttataaatcattgatt

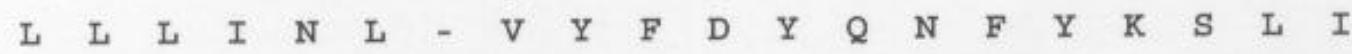
catctggtatctnatatatataaattcgtttacaagtttactagattgaaaatgttgaat $\begin{array}{llllllllllllllllllll}\text { H } & \text { L } & \text { V } & \text { S } & X & \text { I } & \text { Y } & \text { K } & \text { F } & \text { V } & \text { Y } & \text { K } & \text { F } & \text { T } & \text { R } & \text { L } & \text { K } & \text { M } & \text { L } & \text { N }\end{array}$ tttgatgttcaagctc

$\mathrm{F}-\mathrm{C} S \mathrm{~S}$

Homologia com: NADH Desidrogenase da Subunidade ND4L de Spinacia oleracea

Registro de Acesso (Gene Bank): sptrembl|Q9M3I9|Q9M3I9

Probabilidade BLASTX2 $(\mathrm{P})=9.4 \mathrm{e}-15$,

Identidades $=43 / 68(63 \%)$, Positivos $=44 / 68(64 \%)$,

A1B1-8 :

494

LELILNAVNIXLVTFSDFFDSRQL XGNXXXXxxxxxxxxxxxxxxxxxVSSIYRNRKSTRI 315

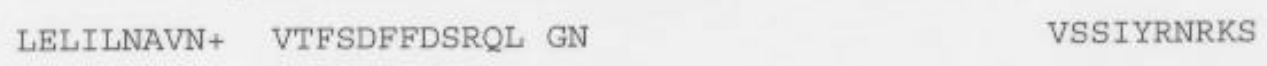

RI

Homólogo 34 LELILNAVNLNFVTFSDFFDSRQLKGNIFSIFVIAIAAAEAAIGPAIVSSIYRNRKSIRI 93

A1B1-8: $\quad 314$ NQSNLLNK 291

NQSNLLNK

HOMÓLOGO: 94 NQSNLLNK 101

FIGURA 4 - Resultado obtido junto ao programa BLASTX2 comparando-se as sequiências de aminoácidos geradas a partir da banda A1B1-8 com as seqüências de aminoácidos do homólogo NADH Desidrogenase. 


\section{Quadro de Leitura (3', + 2) do clone A3B2-1}

gtgcgtcctctcagghaaaggagcagcaaccagcataaccggaaccaaactacctgcagag

$\begin{array}{llllllllllllllllllll}C & V & I & S & X & K & G & A & A & T & \mathbf{S} & I & \mathbf{T} & \mathbf{G} & \mathbf{T} & \mathbf{K} & \mathrm{I} & \mathbf{P} & \mathbf{A} & \mathbf{E}\end{array}$

gataaact tctgadsgbtttcactggattgggaacatagctcttgcatgcgcttacgcta $\begin{array}{llllllllllllllllllll}D & K & I & L & X & X & F & T & G & L & G & T & - & L & I & H & A & I & T & I\end{array}$

ctgtyaattatgatataatggacacattaaagtcccatccatcagaaatavacaatgaaa

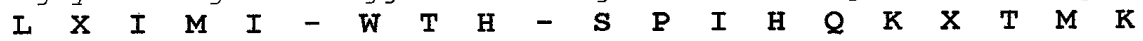

agggctaacgtgctaggggtcacagcaatggcaatattghtcttgctatgcagtggcctt

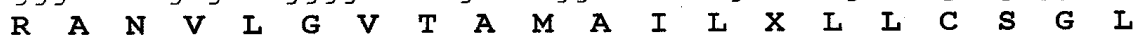

ggctatgctgcttttggtgataacacacctgggaacatcttgactggatttaccgaaccc $\begin{array}{llllllllllllllllllll}\mathbf{G} & \mathbf{Y} & \mathbf{A} & \mathbf{A} & \mathbf{F} & \mathbf{G} & \mathbf{D} & \mathbf{N} & \mathbf{T} & \mathbf{P} & \mathbf{G} & \mathbf{N} & \mathbf{I} & \mathbf{L} & \mathbf{T} & \mathbf{G} & \mathbf{F} & \mathbf{T} & \mathbf{E} & \mathbf{P}\end{array}$

ttctggttggttgcactggggaacggattcatcgtaatccacatgattggagcatatcag

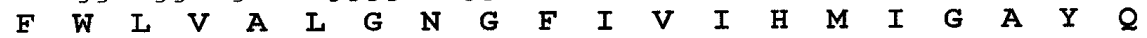
gtgatgggtcaaccattctttcgtatagttgaaataggtgctaacatcgcetggccaagt

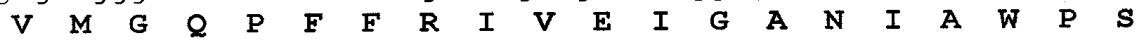
tcagatttcattaacaaggaacatccattcattgtgggcggtttaatggtccgtttcaac $\begin{array}{llllllllllllllllllll}\mathbf{S} & \mathbf{D} & \mathbf{F} & \mathbf{I} & \mathbf{N} & \mathbf{K} & \mathbf{E} & \mathbf{H} & \mathbf{P} & \mathbf{F} & \mathbf{I} & \mathbf{V} & \mathbf{G} & \mathbf{G} & \mathbf{L} & \mathbf{M} & \mathbf{V} & \mathbf{R} & \mathbf{F} & \mathbf{N}\end{array}$ ttgtttagattagtttggaggacgcac

$\begin{array}{lllllllllllll} & \mathbf{L} & \mathbf{F} & \mathbf{R} & \mathbf{L} & \mathbf{V} & \mathbf{W} & \mathbf{R} & \mathbf{T} & \mathbf{H}\end{array}$

Homologia com: Aminoácido transportador (AAP3) de Nepenthes alata

Registro de Acesso (Gene Bank): sptrembl|Q9ZPM5|

Probabilidade BLASTX2 P(2) $=9.6 \mathrm{e}-32$

Identidades $=75 / 153(498)$, Positivos $=101 / 153(668)$

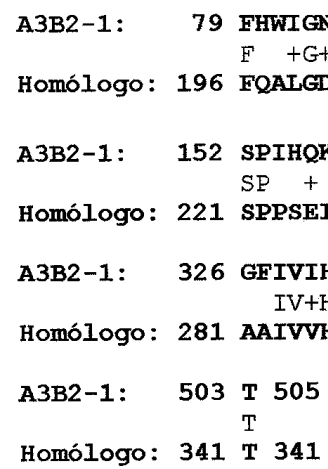

FIGURA 5 - Resultado obtido junto ao programa BLASTX2 comparando-se as seqüências de aminoácidos geradas a partir da banda A3B2-1 com as sequiências de aminoácido transportador (AAP3) RNAm de Nepenthes alata . 
nitrogenados vindos do processo simbiótico certamente seria limitante no processo de enchimento de grãos em soja e, conseqüentemente, um fator-chave na maior ou menor capacidade de suportar períodos de déficit hídrico. A soja é uma espécie que se caracteriza pelo alto teor de proteína de seus grãos.

Esta limitação, dependendo do nível, pode acionar mecanismos de aborto de legumes, objetivando direcionar o fluxo de compostos para os legumes que se apresentam mais adiantados no processo de desenvolvimento e que, em teoria, teriam maiores chances de produzir sementes e, assim, procriar a espécie. Novamente, toda e qualquer hipótese deve ser testada, entretanto, com o presente trabalho sinaliza-se para uma linha de pesquisa que deve ser estudada em maior profundidade no futuro.

\section{REFERÊNCIAS}

ALTSCHUL, S. F.; GISH, W.; MILLER, W.; MYERS, E. W.; LIPMAN, D. J. (1990) Basic local aligment search toll. J. Mol. Biol. 215:403-10.

BEEVER, D. (2000). Os transgênicos e o futuro da agricultura. Biotecnologia e Desenvolvimento. 15: 4-7, 2000.

BERGAMASCHI, H.; BERLATO, M..A.; MATZENAUER, R. (1986). Evapotranspiração máxima da soja e relações com a evapotranspiração calculada pela equação de Penman, evaporação de tanque "classe A" e radiação solar global. Agronomia Sulriograndense, Porto Alegre, v.22, n.2, p.243-59.

BERLATO, M. A. (1981). Carta de aptidão climática da soja no Rio Grande do Sul. In. MIYSAKA, Shiro \& Medina, Júlio César. A Soja no Brasil. Ed 1. São Paulo, 1062p.

BOHNERT, H. J.; NELSON, D. E.; JENSEN, R. G. (1995). Adaptations to environmental stresses. The Plant Cell, 7:1099-1111, 1995.

BRAY, E. A. (1993). Molecular responses to water deficit. Plant Physiol. 103:1035-1040.

BRAY, E.A. (1997). Plant responses to water deficit. Trends Plant Sci. 2: 48-54.
CAMARGO, M. B. P. (1994) Exigências bioclimáticas e estimativa da produtividade para quatro cultivares de soja no Estado de São Paulo. Piracicaba, SP (Tese de mestrado).

DEY, P. M.; HARBORNE, J. B. (1997) Plant Biochemistry. Academic Press, San Diego, CA, $554 \mathrm{p}$.

Embrapa (1998) Centro Nacional de Pesquisa de Soja (Londrina, PR). Recomendações técnicas para a cultura de soja no Paraná 1998/99. Londrina, 201 p. (EMBRAPA-Soja. Documentos, 119).

FAGERIA N. K. (1989) Solos tropicais e aspectos fisiológicos das culturas. $1^{\circ}$ ed. Brasília: Departamento de Publicações EMBRAP-CNPAF, p.381-392.

FARIAS, J.R.B.; NEUMAIER, N.; NEPOMUCENO, A.L. (1995). Efeito da variação diária da umidade do solo sobre a fotossíntese e resistência estomática da soja. In Sociedade Brasileira Agrometeorologia, 9, ed, Anais. Congresso Brasileiro de Agrometeorologia, 9. Campina Grande, PB, pp 68-70.

FARIAS, J. R. B.; NEPOMUCENO, A. L.; NEURMAIER, N. (1993) Rendimento de genótipos semiprecoces de soja submetidos ou não a irrigação, Revista Brasileira de Fisiologia Vegetal, São Carlos, v.5, n.1, p.57, jan/jun.

FISHER, W. N., ANDRE, B.; RENTSCH, D.; KROLKIEWICZ, S.; TEGEDER, M.; BREITKEUZ, K.; Frommer, W.B. (1998) Amino acid transport in plants. Trends Plant Sci. 3:188-195.

FROMMER, W.B.; HUMMEL, S.; UNSELD, M (1995). Seed and vascular expression of a high affinity transporter for cationic amino acids in Arabidopsis. Proc. Natl. Aca Sci. USA, 92:12036-12040.

FREEMAN, W.M.; ROBERTSON, D.J.; VRANA, K.E. (2000). Fundamentals of DNA Hybridization arrays for gene expression analysis. Biotechniques, 29:1042-1055.

GÖPFERT, H.; ROSSETTI, L.A.; SOUZA, J. (1993) Eventos generalizados e securidade agrícola. Brasília: IPEA, Ministério do Planejamento, 78p. 
LEHNINGER, A. L.; NELSON, D.L.; COX, M.M.. (1993). Cell. p. 21-55. In A. L. Lehninger, D. L. Nelson, and M. M. Cox (eds.) Principles of Biochemistry. Worth Publishers, New York.

LEWIN, B. (2000). Genes VII. Oxford University Press, New York, NY, 990p.

LIANG, P.; PARDEE A. B. (1995). Recent advances in Differential Display. Current Opinion in Immunology 7 : 274-280.

LIANG, P.; PARDEE A. B. (1992). Differential Display of eukaryotic messenger RNA by means of the Polymerize Chain Reaction. Science 257: 967-971.

MIYASAKA, S.; MEDINA, J.C. (1981) A soja no Brasil. $1^{\circ}$ ed. São Paulo: ITAL, p.1-174.

NEPOMUCENO, A.L., OOSTERHUIS, D.M., STEWART J.M. (1998). Physiological responses of cotton leaves and roots to water deficit induced by polyethylene glycol. Environmental and Experimental Botany. 40, 29-41.

NEPOMUCENO, A.L.; FARIAS, J.R.B.; NEUMAIER, N. (1994). Efeitos da disponibilidade hídrica no solo sobre a cultura da soja. In EMBRAPA-CNPSo, ed, Ata Documentos 72. Reunião de Pesquisa de Soja da Região Central do Brasil, 15. Londrina, PR, 1994, pp 42-43.

NEUMAIER, N.; FARIAS, J.R.B.; NEPOMUCENO, A.L. (1997). Diferenças no índice de tolerância à seca entre cultivares de soja. In UFU/DEAGO, ed, Ata e Resumos. Reunião de Pesquisa de Soja da Região Central do Brasil, 18. Uberlândia, MG, p 274.

Neumaier, N.; Farias, J.R.B.; Nepomuceno A. L. (1995). Índice de tolerância à seca em quatro cultivares de soja. In Sociedade Brasileira de Agrometeorologia, ed, Anais. Congresso Brasileiro de Agrometeorologia, 9, Campina Grande, PB, pp 80-82.

NEUMAIER, N.; NEPOMUCENO, A.L. (1994). Water management. In FAO - Food and Agriculture Organization of the United Nations, ed, Tropical soybean: Improvement and production. FAO - Plant Production and Protection Series, 27, Rome, Italy, pp 153-160.
SALISBURY, F. B.;AROSS, C.W. (1992). Plant Physiology. Wadsworth Publishing Company, Belmont, CA.

SAMBROOK, J.; FRITSCH, E.F.; MANIATIS, T. (1989). Molecular cloning: A laboratory manual. Cold Spring Harbor Press, 2nd ed., Cold Spring Harbor, NY.

SCHULZE, W.; WOLF, B.F.; JOHN, M. W. (1999) Transporters for ammonium, amino acids and peptides are expressed in pitchers of the carnivorous plant Nephentes. The Plant Journal.17(6), 637-646.

SHINOZAKI, K.; YAMAGUCHI-SHINOZAKI, K. (1996). Molecular responses to drought and cold stress. Current Opinion in Biotechnology 7: 161-167, 1996.

SHINOZAKI, K.; YAMAGUCHI-SHINOZAKI, K. (1997). Gene expression and signal transduction in water-stress response. Plant Physiol. 115: 327-334,1997.

SONG, P.; YAMAMOTO, E.; ALLEN, R.D. (1995). Improved procedure for differential display of transcripts from cotton tissues. Plant Molecular Biology Reporter. 13, 174-181.

SPYCHALLA, J. P.; SCHEFFLER, B. E.; SAWAKINOS, J. R.; Beven, M. W. (1994) Journal of Plant Physiology, 144:444-453.

TURNER, N.C. (1997). Further progress in crop water relations. Advances in Agronomy. 58, 293-338.

WILKINS TA, TURLEY RB, TROLINDER N, KOONCE L, DEVER J, RAJASERKARAN $\mathrm{K}$, ZIPF A, NEPOMUCENO AL (1998) Cotton biotechnology workshop: The rudiments of cotton transformation and biotechnology. pp. 96-99. In National Cotton Council, ed, Proceedings. Beltwide Cotton Conference. San Diego, CA, 1998.

WILKINSON， J. Q.; LANAHAN， M. B.; CONNER, T. W.; KLEE, H. J. (1995). Identification of RNAms with enhanced expression in ripening strawberry fruit using polymerase chain reaction Differential Display. Plant Mol. Biol. 27: 1097-1108. 
